International Journal of Social Science and Economic Research

ISSN: 2455-8834

Volume:06, Issue:05 "May 2021"

\title{
CAPM MODEL AND MODERN PORTFOLIO THEORY
}

\author{
Xiaoting Zhou \\ JSerra Catholic High School, USA \\ DOI: 10.46609/IJSSER.2021.v06i05.003 URL: https://doi.org/10.46609/IJSSER.2021.v06i05.003
}

\begin{abstract}
Mean-Variance Model (Modern portfolio theory) maybe the most famous model in financial field. It assesses a portfolio which's the expected return (mean) is maximized under a given risk (variance). It comes from assumption that investor want as high as return while as low as risk as he could when he invested a couple of assets (a portfolio is the collection of many assets). This model could give us the many optimal portfolio (efficient portfolio frontier) when we know every asset's expect return and their covariance matrix. The accuracy estimating the covariance matrix is the most essential part implementing portfolio optimization.

Thus in this project, we will perform the mean variance portfolio of the targeted portfolio with Ledoit-Wolf shrinkage methodology which can give us robust estimation of covariance matrix. Then we will use the optimal portfolio to visualize the efficient frontier and compare the optimal portfolio with index or other randomly chosen portfolio.
\end{abstract}

\section{Introduction}

This project provides an introduction to mean-variance analysis and the capital asset pricing model (CAPM). We begin with the mean-variance analysis of Markowitz (1952) when there is no risk-free asset also discuss the difficulties of implementing mean- variance analysis in practice and outline some approaches for resolving these difficulties. Because optimal asset allocations are typically very sensitive to estimates of expected returns and covariance, these approaches typically involve superior or more robust parameter estimation methods. Meanvariance analysis leads directly to the capital asset pricing model or CAPM. The CAPM is a oneperiod equilibrium model that provides many important insights to the problem of asset pricing. The language / jargonassociated with the CAPM has become ubiquitous in finance.

\section{Financial Concepts}

- Expected Return: The expected return on portfolio assets is a weighted average of the returns of each asset in the portfolio, often used with a log returns and simple rates of 


\section{International Journal of Social Science and Economic Research}

ISSN: 2455-8834

Volume:06, Issue:05 "May 2021"

return. Since the return of financial assets are mostly in the distribution pattern of peaks and thick tails, the quantitative models mostly usethe log return.

- Volatility: Volatility is used to measure the risk of an asset, the standard deviation of the return sequence. For portfolios, volatility is the standard deviation of the return on the whole portfolio.

- Assets Correlation: If there is a positive correlation between the two assets (correlation coefficient $\rho>0$ ), the price and rate of return between the two assets will change in the same direction, and if there is a negative correlation

- (correlation factor $\rho<0$ ), the price and rate of return between the two assets willchange in reverse." As a result, negative-related assets tend to hedge some of the risk, reducing the overall risk to the portfolio.

- Sharpe Ratio: That is, the profitability of the asset, calculated as: Sharpe $=($ expected return - risk-free interest rate) / volatility

- The higher the Sharp ratio, the greater the benefit of a unit of risk.

\section{About Investors}

- Utility Function: The utility function is a function on $\mathrm{R} \rightarrow \mathrm{R}$, and if the wealth isw, $\mathrm{U}(\mathrm{w})$ represents the utility (satisfaction) that the investor obtains from w; Typically, the utility function $U(w)$ should meet the following criteria:

(1) The more wealth you have, the more utility you have, i.e. $U^{\prime}(w)>0$

(2) Increased wealth and decreasing marginal utility, i.e. U" $(w)<0$

(eg: Wealth increases from $\$ 1$ to $\$ 2$ and the utility is greater than wealthincreases from $\$ 100$ to \$101)

Generally, the utility function will look like as this type of shape: 


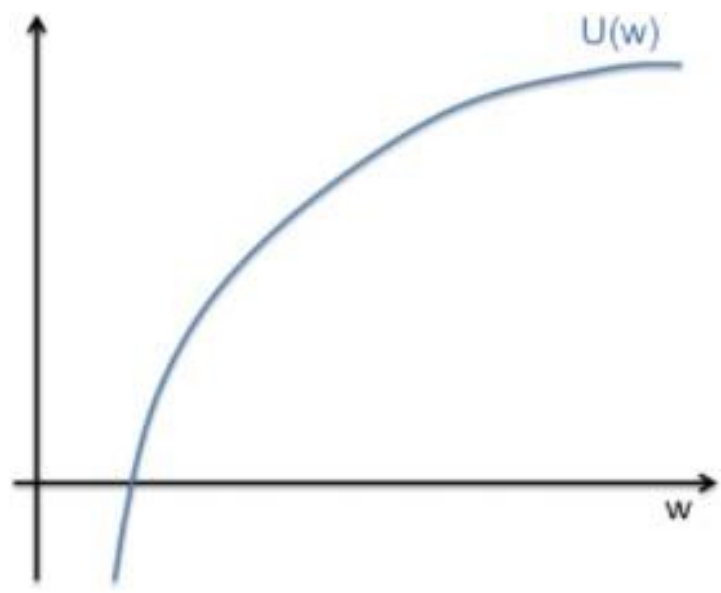

Figure 1.

Utility function normal shape

- Risk Aversion: Starting from utility function, we can define an investor's risk aversion coefficient. Risk aversion coefficient is an extremely important parameter in asset allocation, which reflects the investor's personalized tolerance to risk. The use of ' $a$ ' to represent the risk aversion factor represents an increase in the minimum expected rate of return required by investors for each more unit of risk assumed.

eg: Let risk and expected return be used as the minimum unit of $1 \%$, then $\mathrm{a}=5$ means that investors require a return increase of at least $5 \%$ to be willing to takean additional $1 \%$ risk.

The greater the risk aversion factor, the more conservative the investor is. In general, the risk aversion factor should be greater than zero.

\section{Portfolio Construction}

The reason for choosing these five brands as the experimental targets are following the current trends. Within almost two years, our daily lives are greatly influenced by the pandemic. Our daily habits are changing due to this that wearing masks becomes one of the necessary things we must do before going outside. Therefore, the BYD company becomes my first choice when doing the research. If we protract this further, the company of Disneyland, the model in the field of service, is another example of those whose stocks fluctuate due to the pandemic. From the rootfor research and advanced development, we are seeking for a better life. Then those common things that we are used to have are the targets we need to have a deeper understanding and further awareness. It's undeniable that I am a devoted apple fan, and have utilized the apple products for almost six years and had apple products for daily supplements; I would love to make the apple stock as one of my observation objects. The problems relating to the environment are responsible 
for all the people. Tesla's cars use the electricity as their resources and energy, instead of the coaloil, which contributed a lot for the environmental protection. In addition to the reason for choosing the stock of Tesla, the stock appears to have an unpredictable tendency that the news has both reported that it has jumped greatly and slumped suddenly, which grabs my attention toward it. My last experimental object is the company of Bilibili, which is a Chinese video sharing website, it is really popular among the young age group over the world, and its stock presents an uprising tendency as well which is a good example forstudy.

For the data analysis, the stock price collected is over 251 days (from 3/23/2020 to 3/19/2021) and collected the final closed price for each day. The graph for the Disneyland stock is rising overall, and the lowest price is at our starting date (3/23/2020). This is also the start of the pandemic in the United State and the closed date for Disneyland. And the difference betweenthe highest price and the lowest price is almost 110 dollar, the ratio is almost doubled.

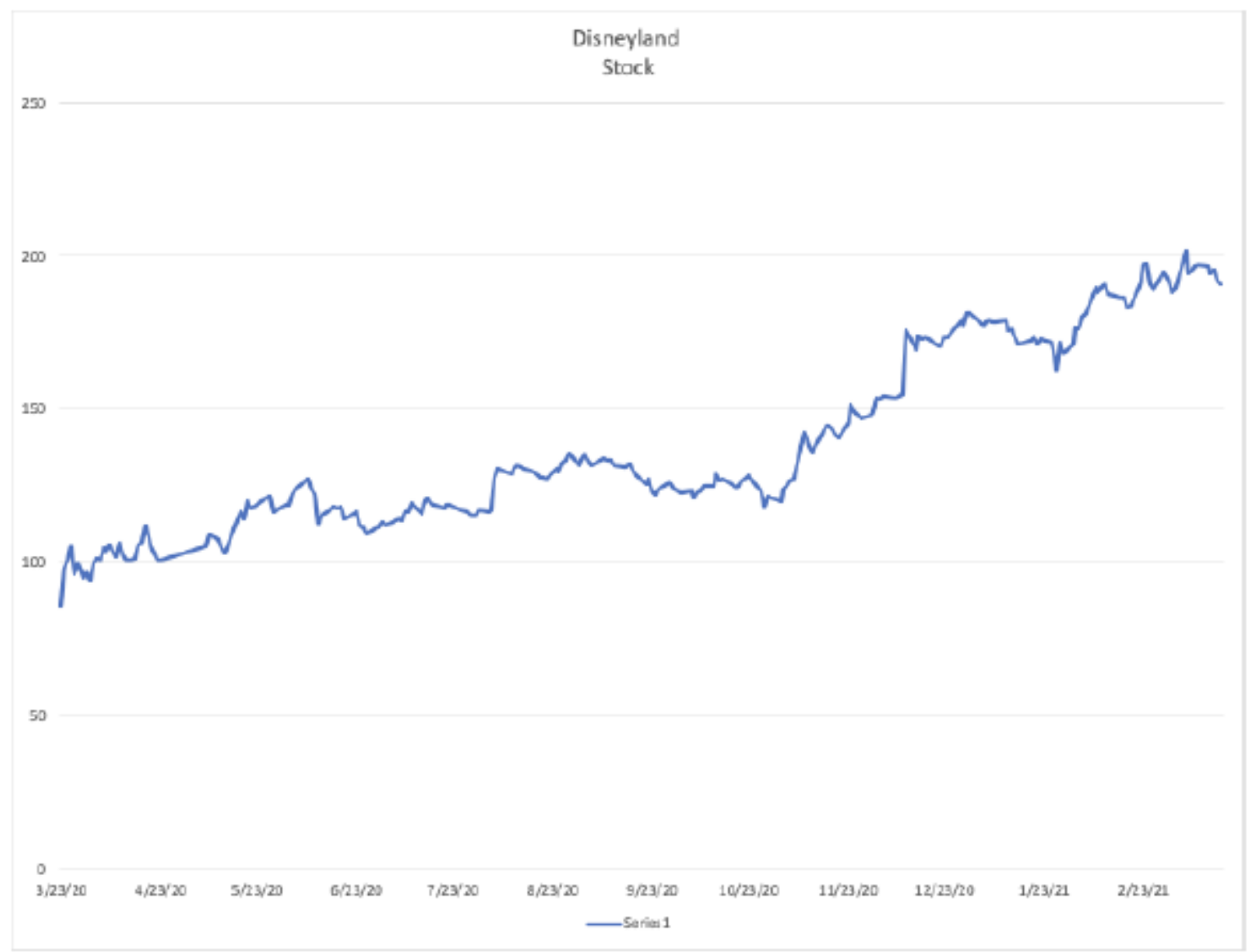


The time period for the company graph is the same as Disneyland. The graph is presented in a positive line. It has the lowest price at the starting point, and recently the line is decreasing.

The difference between the highest price and the lowest price is nearly 80 dollar, which is almost double for it.

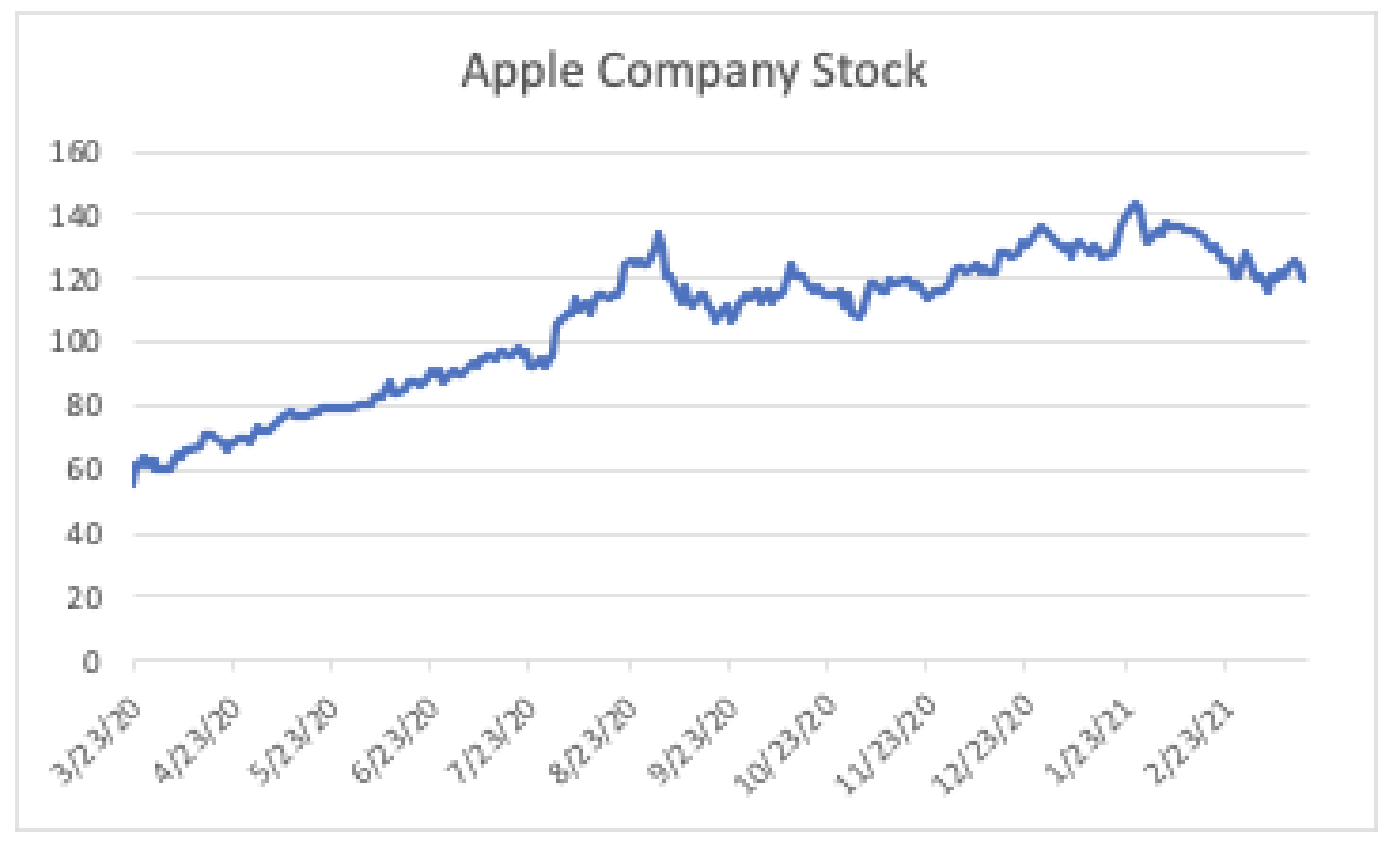

The time period is over 251 days, including the whole pandemic period. The same as the above two, the lowest price is the same as when the Covid started. The overall trend is rising.

However, the stock of Tesla is much more unstable, compared with the previous ones. The difference between the peak and the lowest price is 800 dollar, which is almost eight times greater. 
International Journal of Social Science and Economic Research

ISSN: 2455-8834

Volume:06, Issue:05 "May 2021"

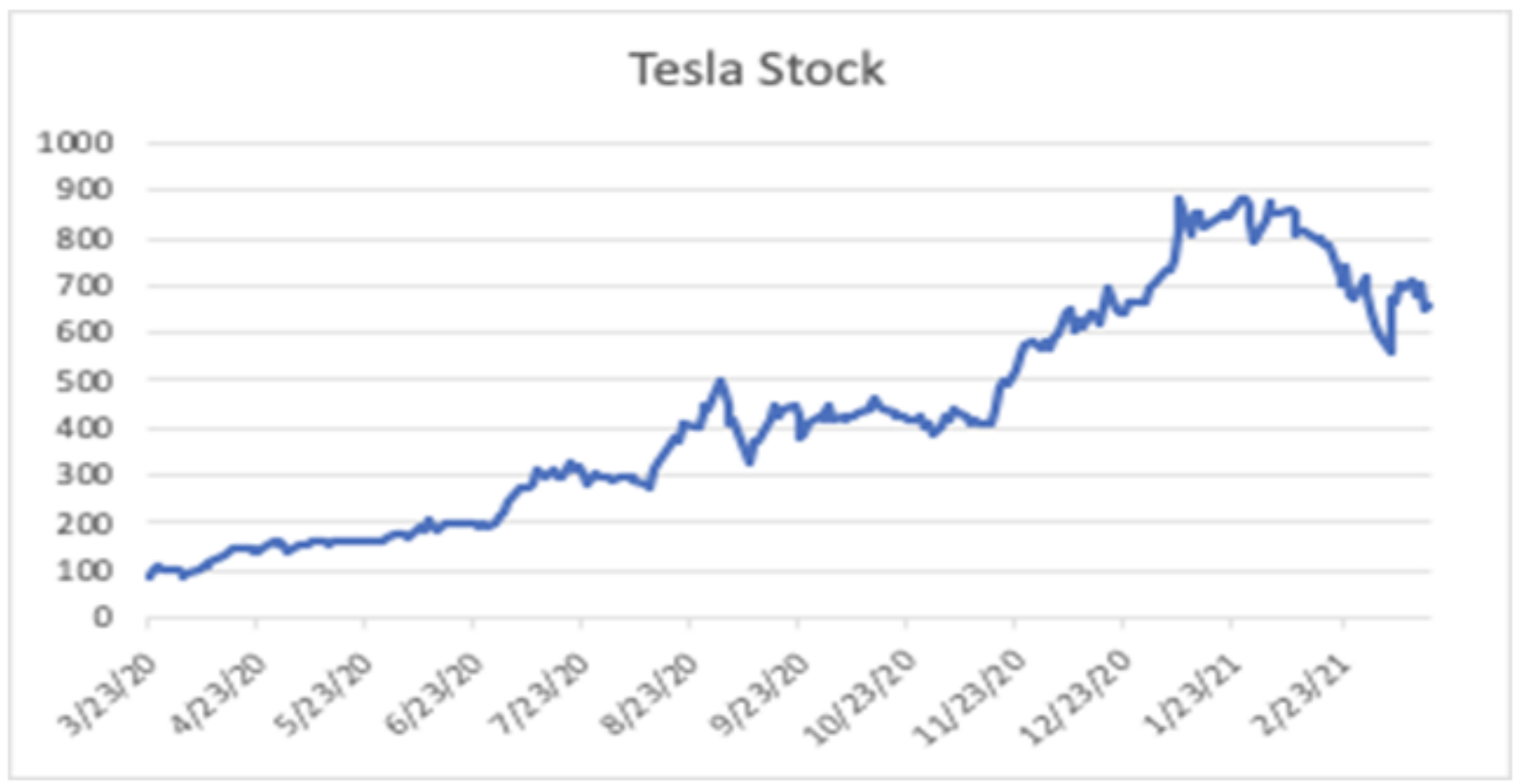

This graph is scaled over 251 days, and the entire tendency can be concluded as a rising trend with a little fall recently. For the lowest point, it stays at the beginning of the graph and it climbs slowly in 2020. However, it instantly increases in the January of 2021 (which is also the time for the turning point of Covid in China). The difference between the highest point and the lowest point is 80 dollar.

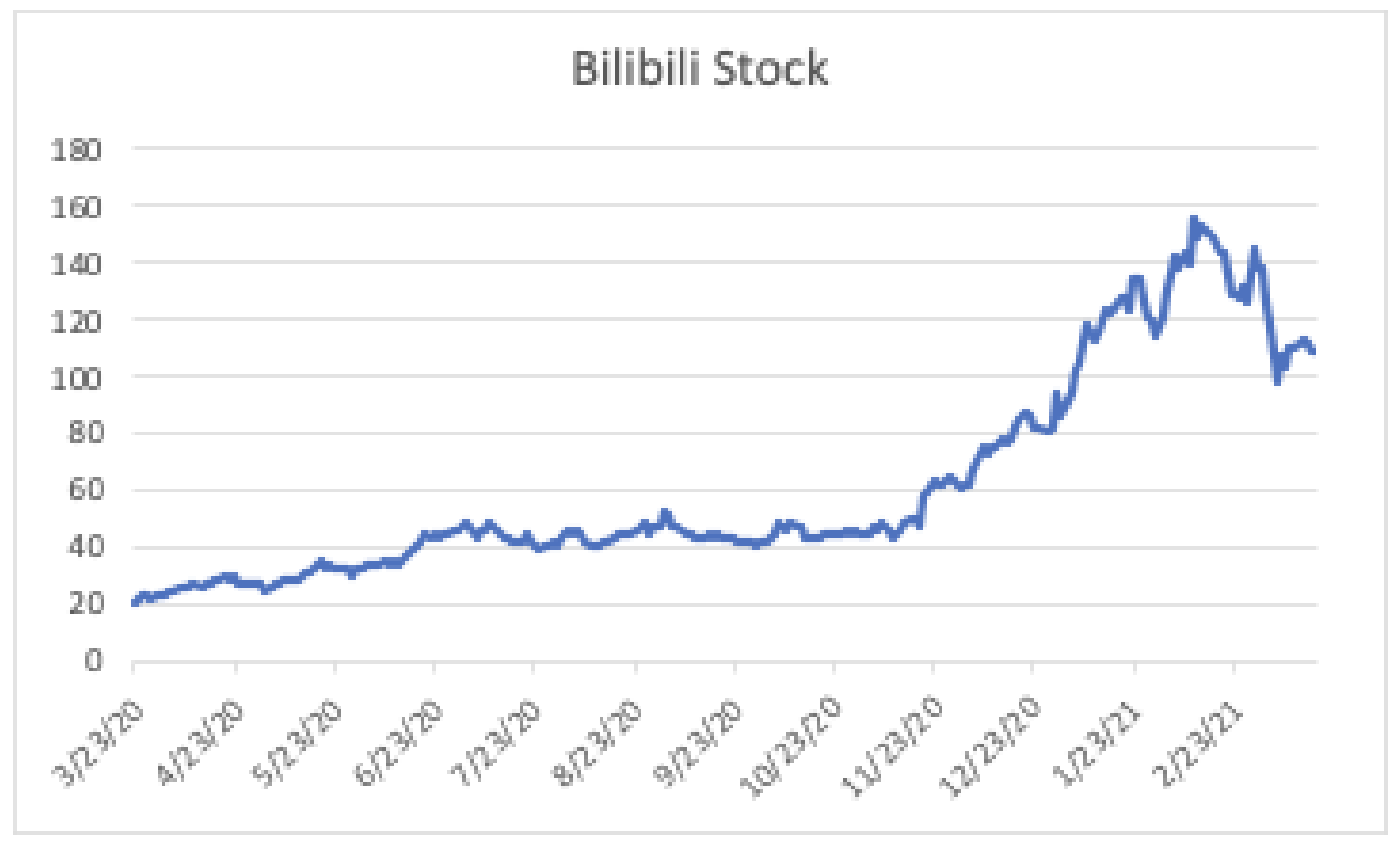


This graph is also based on 251 days period of time, and it appears with the positive line. The lowest point started at the beginning of our graph. It accelerates until February in 2021, with a small decline. The difference between the peak and the dimp is 30 dollars, not too much compared with other stocks; however, it is indeed a big difference for this stock.

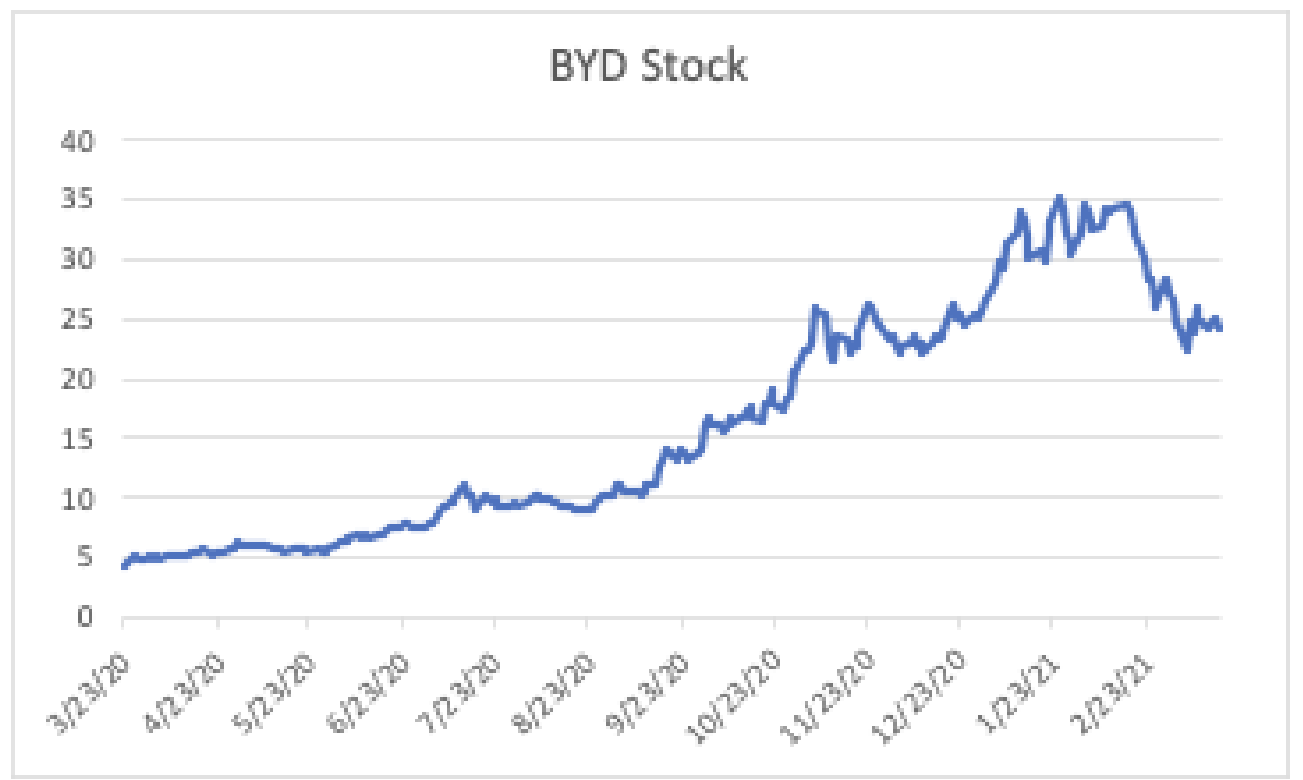

In conclusion, these five stocks all presented rising trends with the lowest point at the beginning of the pandemic. Which somehow matches our theory that the Covid indeed influences people's life even on a bigger scale. According to these five graphs and the calculated difference, we still cannot determine which one is safe to invest; or in other words, we still cannot decide which one is more likely to benefit or less likely to deficit. Moreover, we should step out of only one situation, we need to consider the whole invested stock as a whole. Therefore, Modern Portfolio Theory is introduced in these kinds of evaluations. 
International Journal of Social Science and Economic Research

ISSN: 2455-8834

Volume:06, Issue:05 "May 2021"
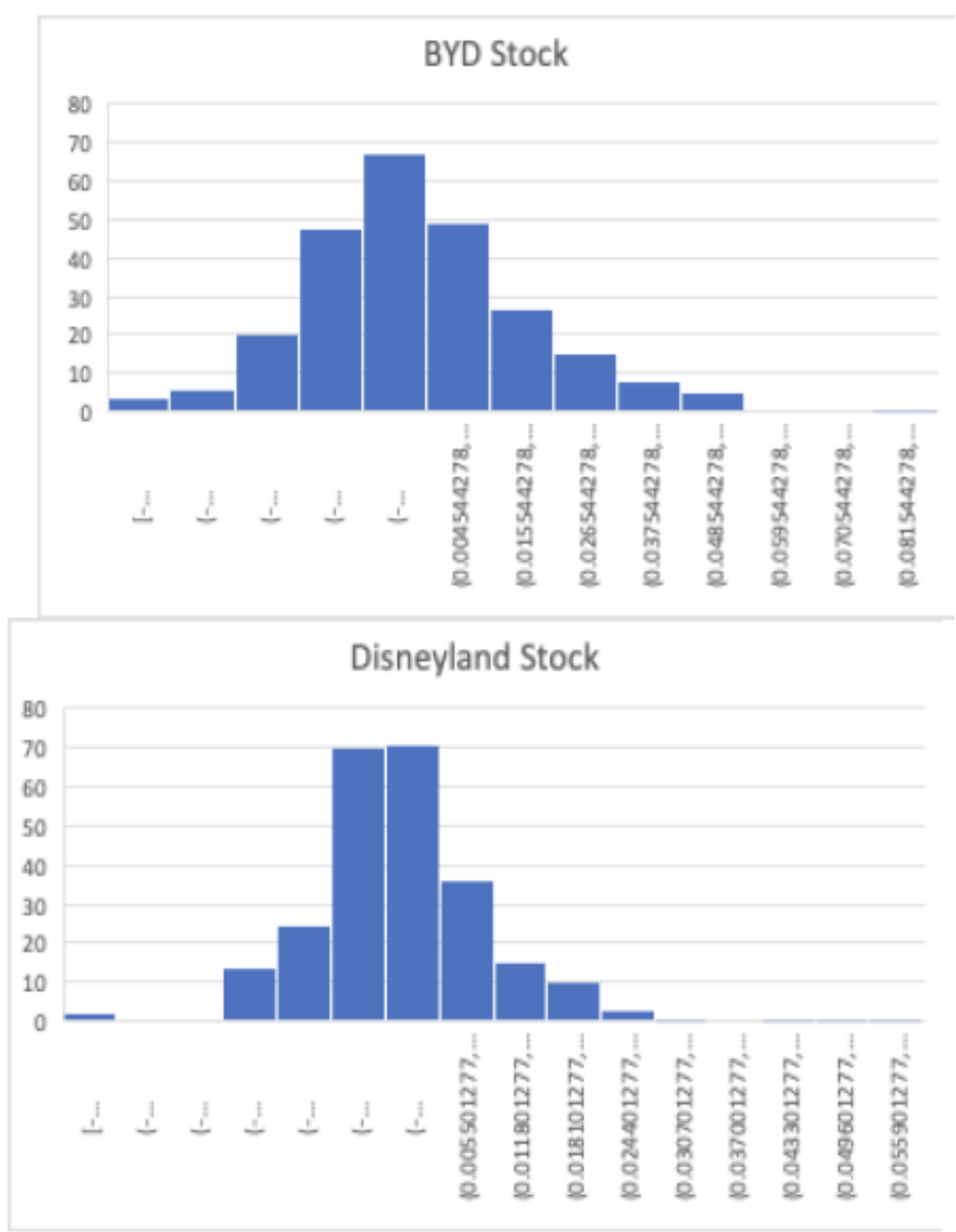
International Journal of Social Science and Economic Research

ISSN: $2455-8834$

Volume:06, Issue:05 "May 2021"

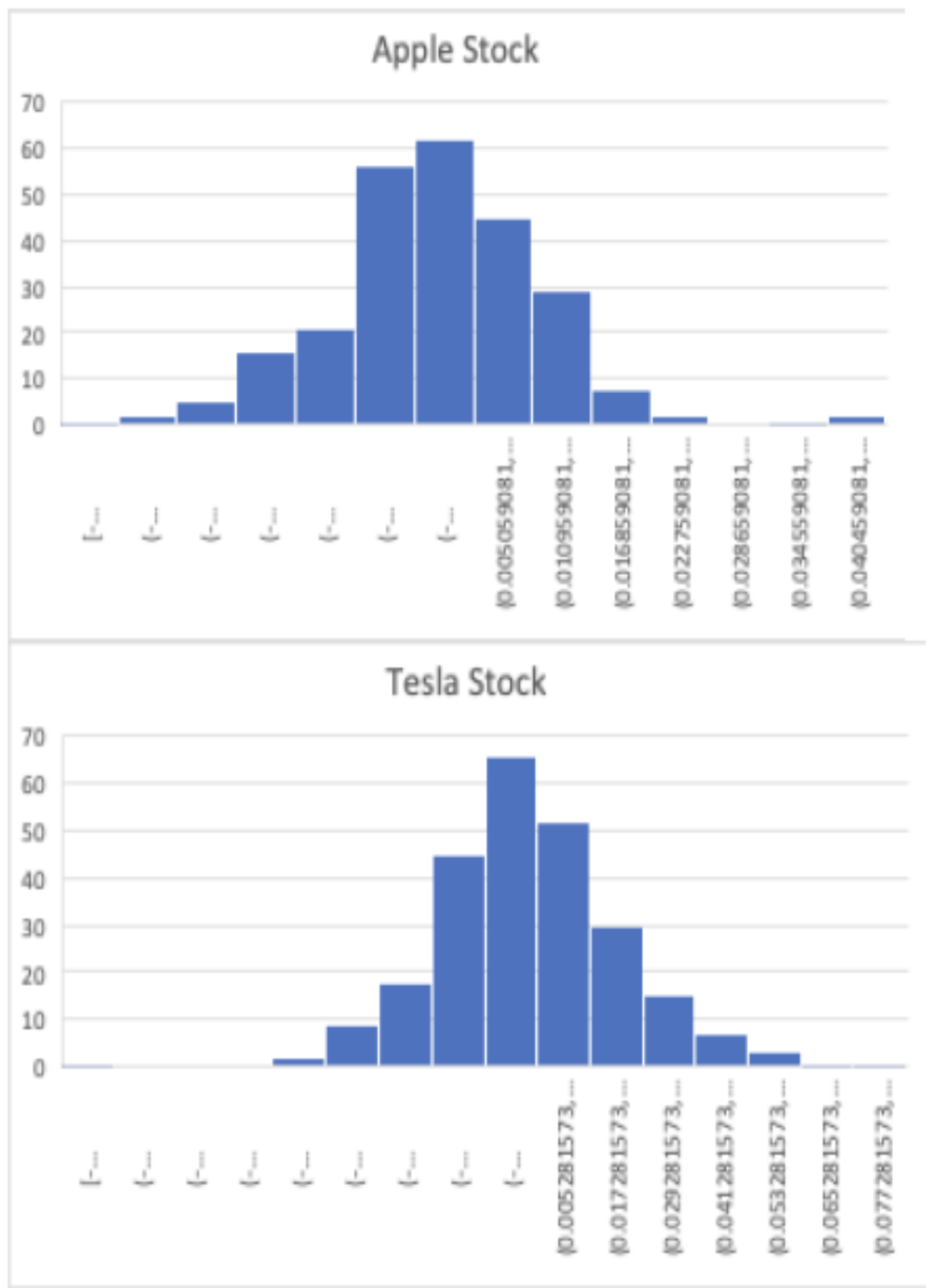


International Journal of Social Science and Economic Research

ISSN: 2455-8834

Volume:06, Issue:05 "May 2021"

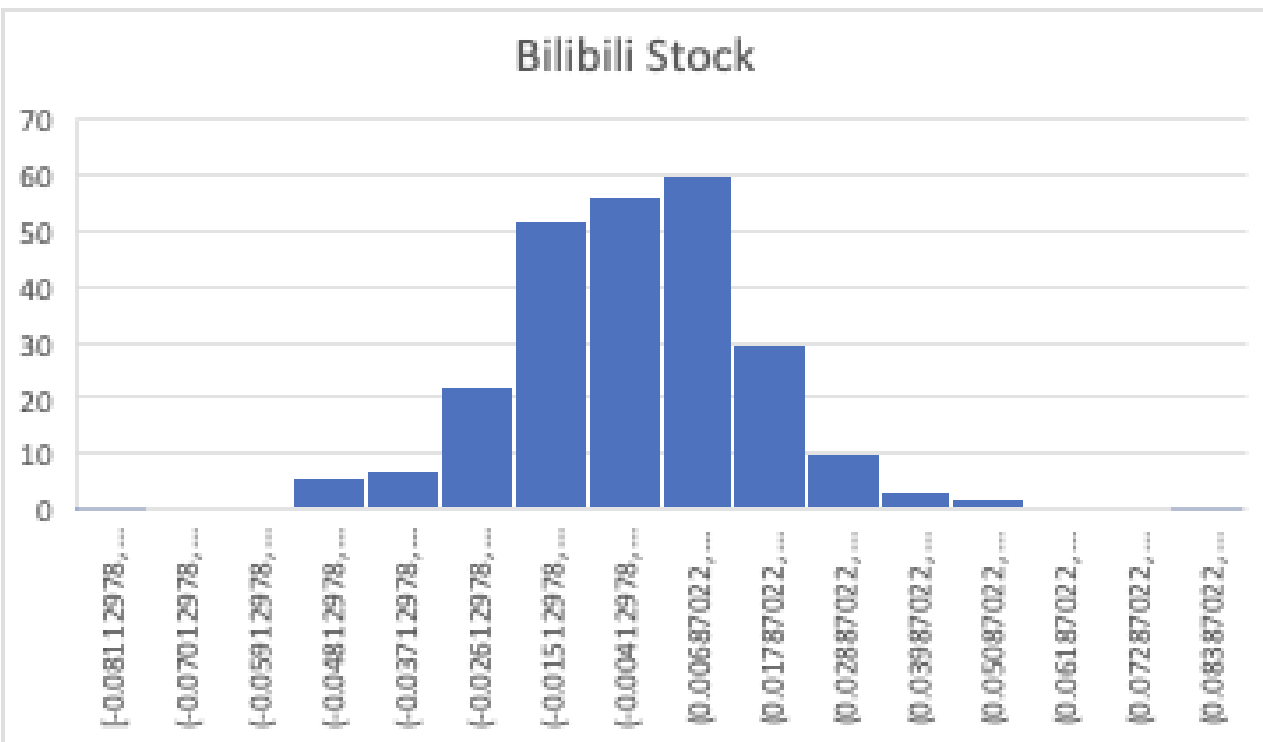

\section{Methodology Overview}

Modern Portfolio Theory refers that an investment's risk and return should not be considered as a single object, we should think about the whole image of how this investment will affect the entire portfolio. And Modern Portfolio Theory suggests that we should make a portfolio of several assets to determine how to get the maximum benefits at a given level of risk. To be easier to understand is that MPT qualifies the theory that do not put all your eggs in one basket. The assumption in the MPT is that we assume our consumers are risk-averse investors, which means they are willing to have less risk.

We will also utilize the mean variance optimization in MPT, to determine how the investors would like to invest when they have the full-knowledge of their stocks. This is also called the diversification which is a strategy to reduce the risk for the total investments without reducing any returns. There are two elements in the mean variance optimization: the variance and the expected return. In MPT, the investors would like to choose different levels of securities (the equalities and debts) by selecting the demanded value of the variance and expected return.

\section{Objective Function}

In general, portfolios have two objectives: to maximize returns and minimize risk. The goal of optimization is therefore to find a balance that tends to maximize returns or minimize risk, depending on the investor's risk aversion. Assuming that there are $\mathrm{n}$ assets in the portfolio, $\mathrm{R}$ is the rate of return for the entire portfolio. 
Objective function:

$$
\begin{aligned}
& \operatorname{maximize} E(R)-a w^{T} \Sigma w \\
& \leftrightarrow \operatorname{maximize} r^{T} w-a w^{T} \Sigma w
\end{aligned}
$$

Where $\mathrm{w}$ is the asset weights in the portfolio ( $\mathrm{w} \in[0,1]$ ), a is the risk aversion, $\Sigma$ is the return covariance matrix.

\section{Constraints}

The most critical constraint is that the weight of the asset adds up to 1 .

$$
\sum_{i=1}^{n} w_{i}=1
$$

You can specify a weight limit for each asset.

\section{Define Risk Aversion Value}

There are some common utility functions:

- Exponential utility function $U(w)=-e^{-a w} ; a>0$

- Logarithm utility function $U(w)=\ln (w) ; w>0$

- Power utility function $U(w)=\stackrel{w^{1-b}}{ } ; b>0 ; w>0, b \neq 1$

Utility functions can be used to determine an investor's level of risk aversion- thelarger the recess of the utility function (i.e., the more negative $U^{\prime \prime}(w)$ ) represents the greater the amount of wealth that needs to be added in order to increase a unit of utility. This demonstrates that the investor is more risk averse.

\section{Optimization Calculation}

With above objective function and the introduction of risk aversion, we can transform the objective function into following from: 


$$
\begin{gathered}
\operatorname{minimize} \frac{1}{2} w^{T} \Sigma w-\frac{1}{a} \mathrm{r}^{\mathrm{T}} w \\
\text { subject to } \mathrm{e}^{\mathrm{T}} w=1
\end{gathered}
$$

where $\mathrm{e}$ is a vector contains all elements as 1 . Let's denote $\lambda=1 / \mathrm{a}, \lambda>0$ Now the KKT condition is:

$0=\Sigma w-\lambda w-\gamma e$

$$
\mathrm{e}^{\mathrm{T}} w=1
$$

$$
\mathrm{e}^{\mathrm{T}} w=1
$$

With above two equations, we can have: $\gamma=\frac{1-\lambda w^{T} \Sigma^{-1} e}{e^{T} \Sigma^{-1} e}$

Denote $w 1=\frac{\Sigma^{-1} e}{e^{T} \Sigma^{-1} e}$ and $w 2=\frac{\Sigma^{-1} w}{e^{T} \Sigma^{-1} w}$

Then the optimal solution of the whole system should be:

$$
w_{\text {opt }}=(1-k) w 1+k w 2
$$

Where $\mathrm{k}=\lambda w^{T} \Sigma^{-1} e$

\section{Model Construction Workflow}

We first provide a procedure overview of the model construction: 


\section{International Journal of Social Science and Economic Research}

\section{Data Preparation}

- Log return calculation

- Preprocess missing values and outliers

- Estimate covariance matrix

\section{Model Construction}

- Define objective function and constraints

- Write Python codes to find the results

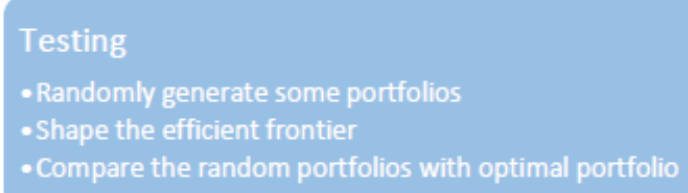

\section{Data Source}

The monthly return data for five stocks was extracted from Google Finance with the stock tickers: DIS, AAPL, DIS, TESLA, BYDDF

The necessary data is the daily adjusted closing price of the asset, if the unadjusted closing price is used, the yield needs to be adjusted according to the stock dividend, stock split and other events, so as to avoid causing abnormal return.

\section{Data Preprocessing}

- The log return is calculated from the current price and the previous month's adjusted closing price.

- The missing value of return can be replaced by the historical average rate of return (Note: it is not recommended to replace the missing price data directlywith the average price)

- Return values which are outside than 3 standard deviations are removed directlyas outlier values (This can be adjustable for known return distributions) 
International Journal of Social Science and Economic Research

ISSN: 2455-8834

Volume:06, Issue:05 "May 2021"

- The return co-variance matrix estimation:

Highly related assets can have a significant impact on optimization results. Here we give two ways to adjust the yield co-variance matrix calculated using historical data.

1. Diagonal adjustment - A very small number (e.g. 0.001, 0.005) is added uniformly tothe main diagonal of the yield co-variance matrix, thus ensuring that the result error is not magnified when we inverse the matrix.

2. Ledoit-Wolf shrinkage - Using Ledoit-Wolf shrinkage method to acquire robust covariance matrix estimation.

\section{Optimizer Construction}

We are using python and package scipy which provides a convenient API to build all kinds of minimization problem structure. Then the constraints are introduced by adding inequality or equality.

Here we restricted every asset has upper bound allocation percentage of $30 \%$ and haslower bound allocation percentage of $0 \%$, which means no short sells are allowed.

\section{Model Results}

\section{Optimal Portfolio Information}

The concept of the optimal portfolio to be simply to say is find somewhere perfectlybalanced the risk and the return without being "inefficient", to give the data for the highest return at the given risk, or the lowest risk at a given return.

\section{Efficient Frontier}

This a curve formed by thousands of the optimal portfolio, which gradually become afrontier. For the whole scatterplot, the $\mathrm{x}$-axis is the standard deviation of the return, which we considered this as a measure of the risk. Then for the y-axis will be the expected return for the entire portfolio. And the relationship between the risk and expected return is positive, which means an increase in risk will result an increase in expected returns. In this experiment, the risk aversion is the independent value, then the whole analysis is based on the changing in risk to find out the maximum expected return. And every single point on the efficient frontier will be our optimal return of theportfolio at that given risk aversion. 
International Journal of Social Science and Economic Research

ISSN: 2455-8834

Volume:06, Issue:05 "May 2021"

\section{Results Insights}

Firstly, we found out our expected return for each of stock at a given risk aversion. It isclear to say the relationship between the return and the risk is positive, which means the higher risk aversion will lead to the lower return and also the lower risk.

$$
a=0 \quad a=2 \quad a=5 \quad a=10
$$

$\begin{array}{lllll}\text { AAPL } & 0.000000 & 0.000000 & 0.124502 & 0.188918\end{array}$

$\begin{array}{lllll}\text { TSLA } & 0.600000 & 0.378233 & 0.247314 & 0.184951\end{array}$

DIS $\quad 0.000000 \quad 0.044526 \quad 0.174994 \quad 0.233582$

$\begin{array}{lllll}\text { BYDDF } & 0.218992 & 0.292281 & 0.226792 & 0.194983\end{array}$

$\begin{array}{lllll}\text { BILI } & 0.181008 & 0.284960 & 0.226398 & 0.197565\end{array}$

\begin{tabular}{|c|c|c|c|c|}
\hline \multicolumn{5}{|c|}{ Asset Allocation Table } \\
\hline & $a=0$ & $a=2$ & $a=5$ & $a=10$ \\
\hline Volatility & 0.052570 & 0.045333 & 0.036921 & 0.034698 \\
\hline Expected Return & 0.007565 & 0.007117 & 0.006018 & 0.005488 \\
\hline Sharpe Ratio & 0.143912 & 0.157000 & 0.162989 & 0.158158 \\
\hline
\end{tabular}

\section{Portfolio Information Table}

Then according to all the data, we collected, we try to find our efficient frontier for the whole portfolio.

The red point below shows the optimal portfolio information at risk aversion equals to This is at the $0.7564 \%$. According to our selected stocks, only the stock of Tesla is close to this with a expected return of $0.6 \%$. As the risk aversion is zero, which we can conclude that if the investors want to have the lowest risk with a great return, the Tesla among those five will be the best choice. The rest of those would be inefficient to receive that expected return. Especially, the expected return for Apple and Disneyland at risk aversion 0, are almost zero, indicates that if the 
investors want to have the low risk, the Apple and Disneyland are their last choice to choose due to it has no return forthem at such a low risk.

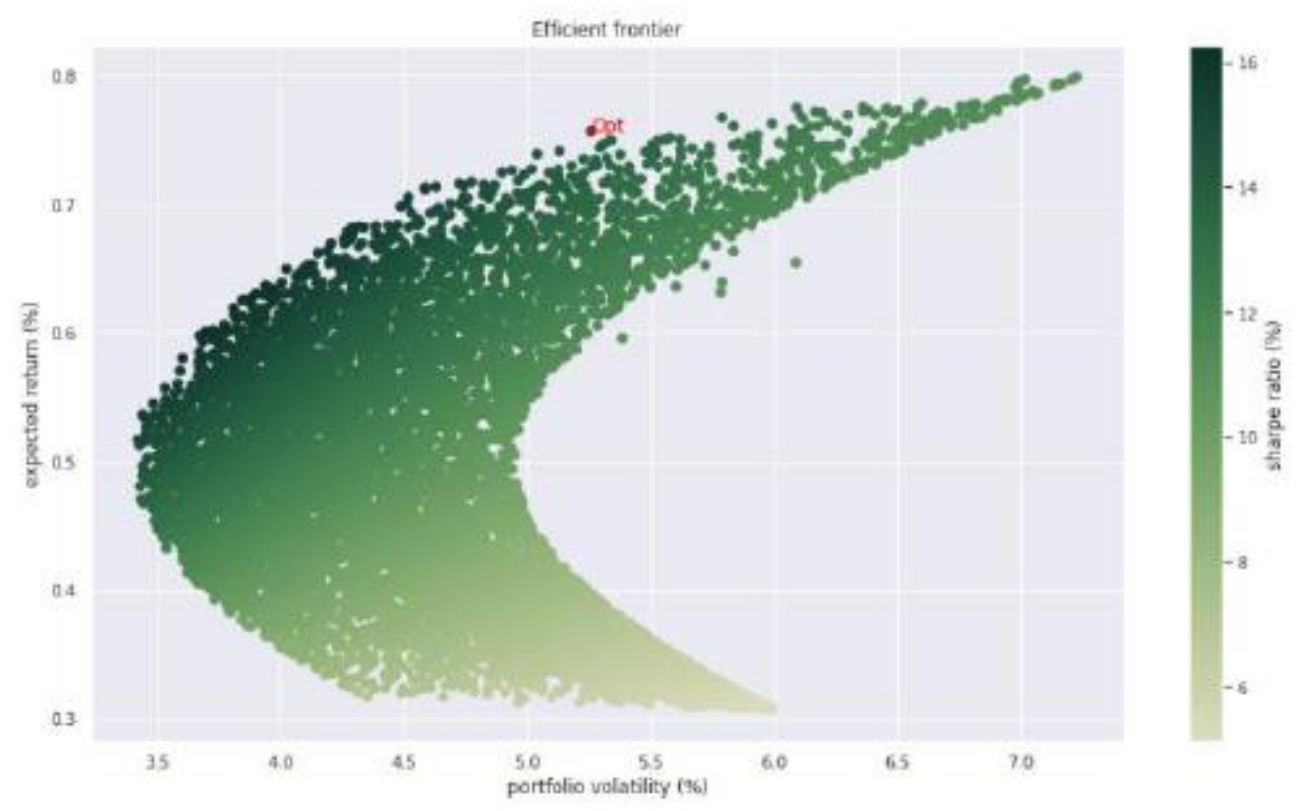

\section{Efficient Frontier When $\mathrm{A}=0$}

When the risk aversion increases to 2, the expected return for all five would like to increase respectively. And the optimal portfolio expected return is $0.7117 \%$-the increase in not very much comparing to the expected return for the risk aversion 0 . For this one, none of our five stocks have reached this point, which means all five are ongoing inefficient. The closest to this point is the stock of Tesla's 0.3782 is our best choice for this risk aversion 2. However, the stock of Disneyland will be last option to choose due to its lowest expected return at this given risk. 


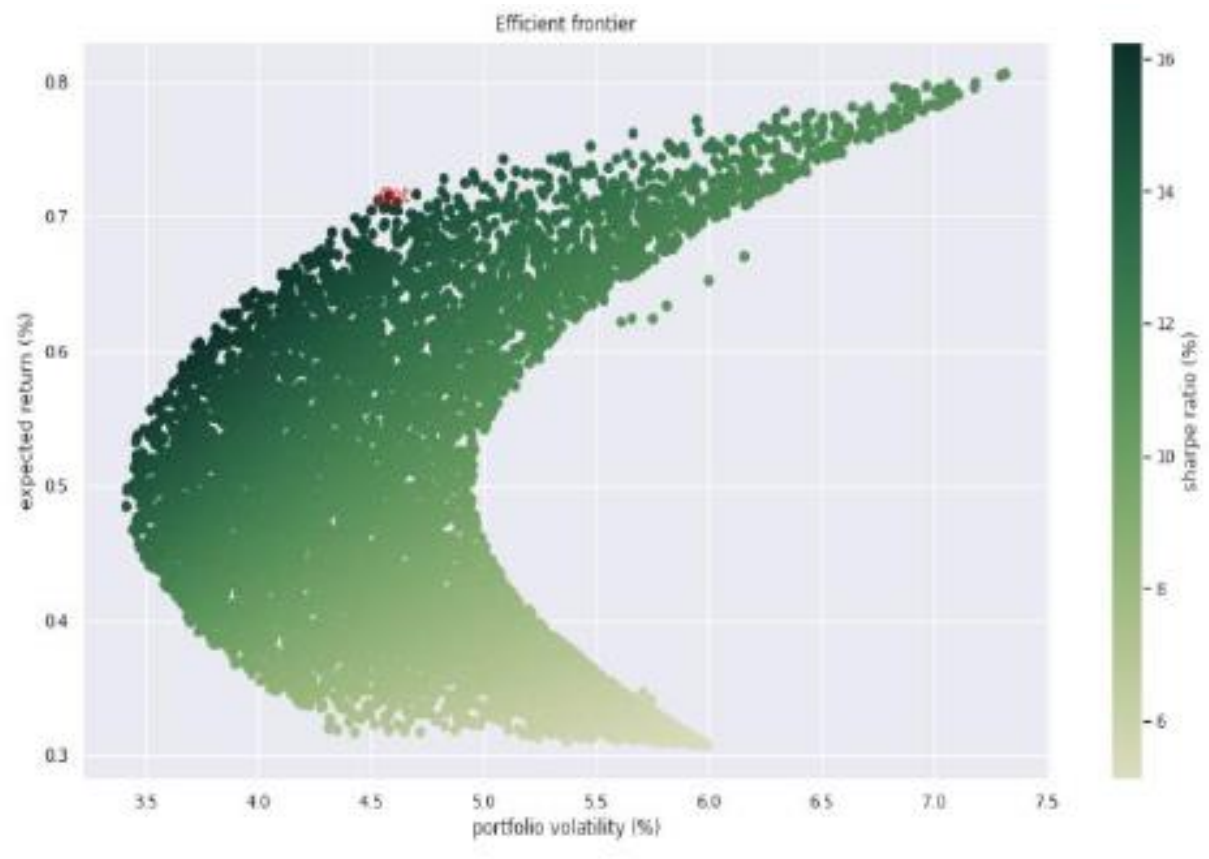

\section{Efficient Frontier When $\mathrm{A}=2$}

When the risk aversion reaches at 5, the maximum expected return will be $0.6018 \%$ according to the optimal portfolio information. Then comparing this to the value for the stocks, the stock for Tesla is still the best choice that although it still is far from the optimal, it has the maximum expected return at risk return equals to 5 among these five stocks. And the stocks for Apple and Disneyland both are our last choices due to their low return at this level of risk. 


\section{International Journal of Social Science and Economic Research}

ISSN: 2455-8834

Volume:06, Issue:05 "May 2021"

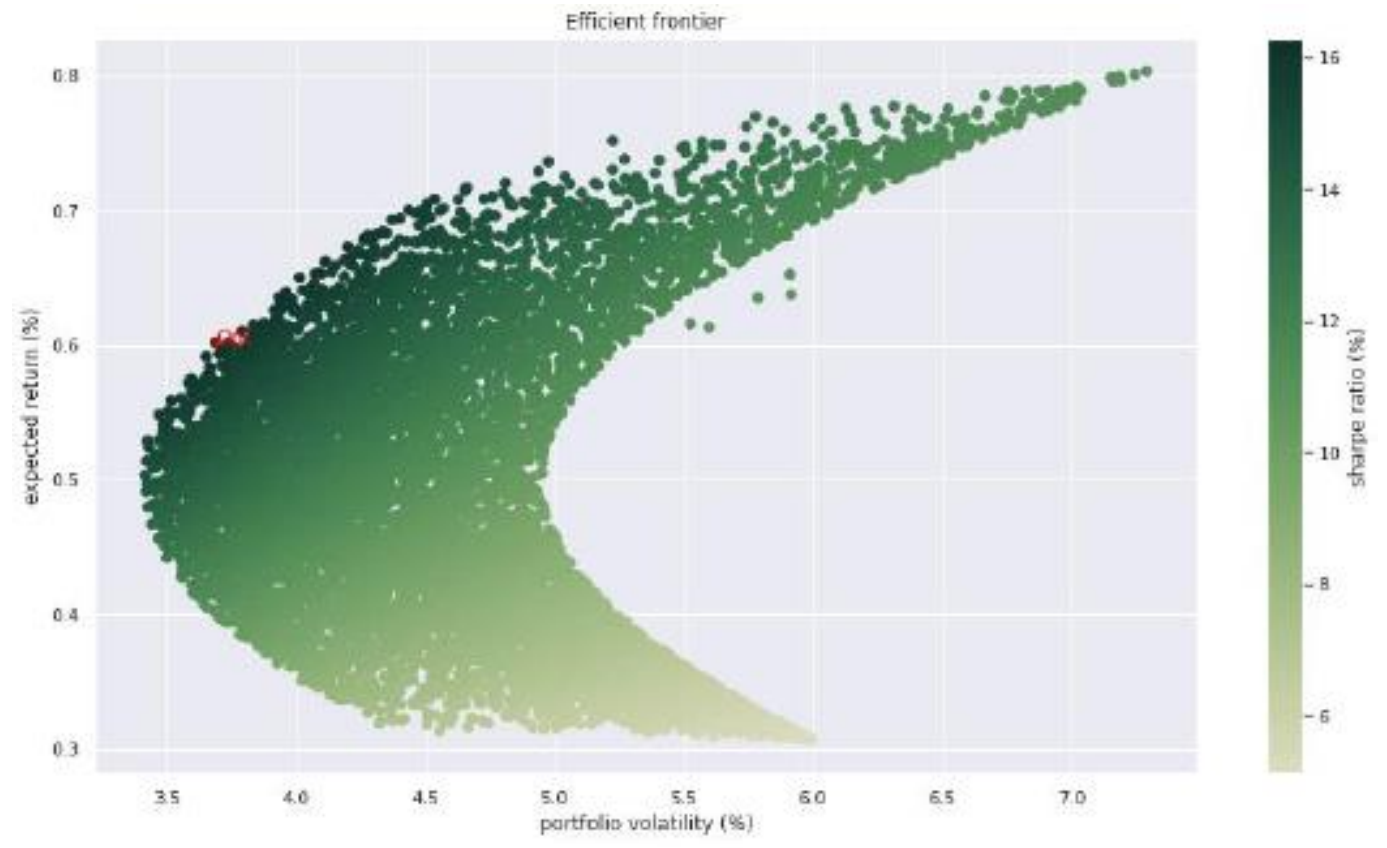

Efficient Frontier When $\mathrm{A}=5$

Increasing the risk aversion equal to 10 , the maximum expected return will be $0.5488 \%$. The situation for this risk is totally different to the previous ones that the stock of Tesla become out of consideration because of its low expected return at this. Then the stock of Disneyland become best choices among these five with its highest expected return. 


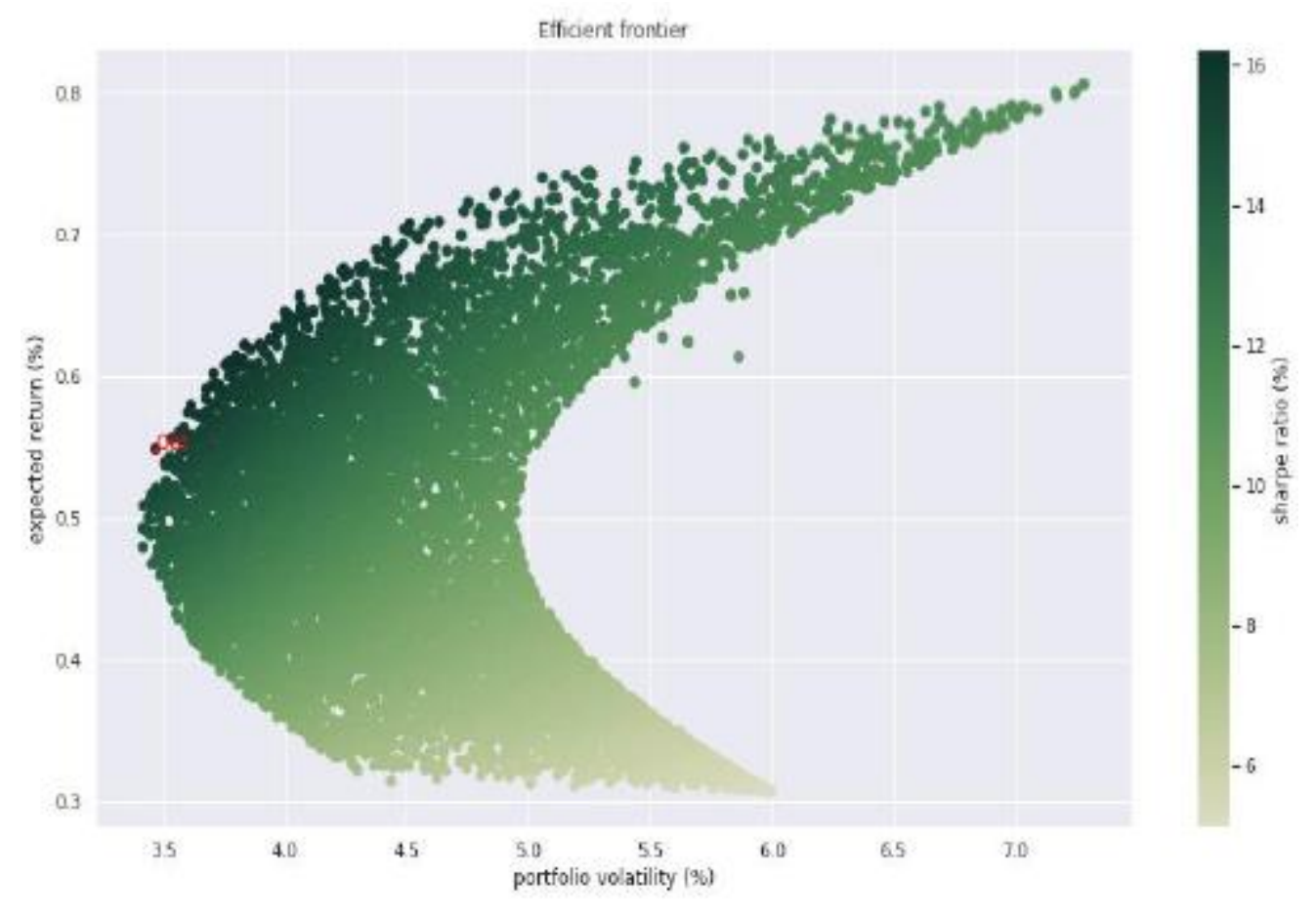

Efficient Frontier When $\mathrm{A}=10$

In conclusion, the stock of Tesla will be the best choices to choose from due to its high expected return over this approximately one-year period. Especially, if the investors want to have no risk, it met the optimal point. Nonetheless, if protract the whole thingsfurther, the stock of Disneyland will be the best choice for those who are willing to receive much more returns (at high risk).

\section{Conclusion}

Based on the actual financial market, this project has coded the traditional Markowitz asset allocation model. This is an asset optimization method based on risk aversion factors, yields and volatility. This asset allocation model can be used for a variety of asset types, such as stocks, bonds, or indices. The allocation of asset weights for the next period is optimized based on the previous return and volatility of the asset.

Markowitz asset allocation model is a financial gain/risk trade-off, which lays a solid theoretical foundation for CAPM model.

\section{Reference}

[1] Ledoit, Olivier, and Michael Wolf. "Improved estimation of the covariance matrix of 
International Journal of Social Science and Economic Research

ISSN: 2455-8834

Volume:06, Issue:05 "May 2021"

stock returns with an application to portfolio selection." Journal of empirical finance 10.5 (2003): 603-621.

[2] Roll, Richard. "A mean/variance analysis of tracking error." The Journal of Portfolio Management 18.4 (1992): 13-22.

[3] Mangram, Myles E. "A simplified perspective of the Markowitz portfoliotheory." Global journal of business research 7.1 (2013): 59-70.

[4] Virtanen, Pauli, et al. "SciPy 1.0: fundamental algorithms for scientific computing in Python." Nature methods 17.3 (2020): 261-272.

[5] Google Finance: Stock market quotes, news, currency conversions \& more. (n.d.).Google. Retrieved October 11, 2020, from http://www.google.com/finance

[6] Erlich, István, Ganesh K. Venayagamoorthy, and Nakawiro Worawat. "A mean-variance optimization algorithm." IEEE Congress on Evolutionary Computation. IEEE, 2010. 